\title{
Formulación, elaboración y análisis sensorial de la gelatina obtenida a partir de la pata de pollo (Gallus gallus)
}

\author{
Jorge Cañari, Yadira Cairo
}

Laboratorio de Nutrición y Dietética E.A.P. de Nutrición, UNMSM, Lima-Perú

Objetivos: Formular y elaborar gelatina a partir de la pata de pollo, con buenas características sensoriales.

Diseño: Tecnológico experimental.

Institución: Laboratorio de Nutrición y Dietética E.A.P. de Nutrición, UNMSM, Lima-Perú.

Participantes: Personas adultas de 18 a 50 años de edad.

Intervenciones: Se elaboró la gelatina a partir de la pata de pollo y se formuló en tres concentraciones. Se seleccionó a 27 panelistas no entrenados para la prueba de aceptación (características organolépticas: color, olor, apariencia y sabor) y 7 panelistas entrenados para la prueba de discriminación (textura).

Principales medidas de resultados: Obtención de la gelatina en tres concentraciones.

Resultados: Se obtuvo gelatina de pata de pollo con un $30 \%$ de rendimiento. Las formulaciones obtenidas fueron:

Formulación A: 100\% (sin sustitución); Formulación B: 75\%; Formulación C: 50\%; hubo diferencias significativas entre el color y sabor $(p<0,05)$. En la prueba de discriminación se evaluó la textura: Formulación $A(6,7)$; Formulación $B(5,85)$; Formulación C $(5,57)$; hubo diferencias significativas $(p<0,05)$, resultando la Formulación $A$ diferente a la Formulación $\mathrm{B}, \mathrm{C}$ y al Patrón.

Conclusiones: La Formulación C tuvo mayor aceptación. Este producto puede ser usado en la industria alimentaria. Palabras clave: Gelatina, prueba de aceptación, prueba de discriminación. 